\title{
Neuroendocrine control of ovarian function in the primate
}

\author{
Michel Ferin
}

College of Physicians and Surgeons, Columbia University, New York, New York 10032, U.S.A.

\begin{abstract}
Summary. This article reviews the neuroendocrine factors which control the menstrual cycle in the macaque monkey. It describes the pulsatile characteristics of gonadotrophin secretion, the control of LH pulses by an arcuate neural Gn-RH oscillator and the significance of pulsatile Gn-RH secretion. The factors which may modulate the activity of the Gn-RH arcuate neural oscillator are anaesthesia, ovarian hormones and endogenous opiates, as well as the possible significance of changes in Gn-RH pulsatile characteristics. Finally, the oestrogen and progesterone feedback control of the midcycle gonadotrophin surge and the site of action (hypothalamic or hypophysial) of these steroids are contrasted in the monkey and rat.
\end{abstract}

This article, which reviews salient features of the neuroendocrine mechanisms controlling the menstrual cycle, is based on experimental results obtained in several primate research centres as well as our laboratory, using the macaque monkey as a model. The length of the menstrual cycle and the pattern of hormonal secretion in this animal indeed replicate closely those of the human. The article will underline the physiological features of gonadotrophin secretion and of its control and modulation by hypothalamic and ovarian hormones.

Mean levels of gonadotrophins and of ovarian steroids throughout a menstrual cycle in monkeys are illustrated in Text-fig. 1. Briefly, follicular maturation is characterized by increasing circulatory oestradiol concentrations, which reach a peak at the time of the mid-cycle LH and FSH surges. This gonadotrophin surge in turn induces ovulation (in about $36 \mathrm{~h}$ ), followed by the transformation of

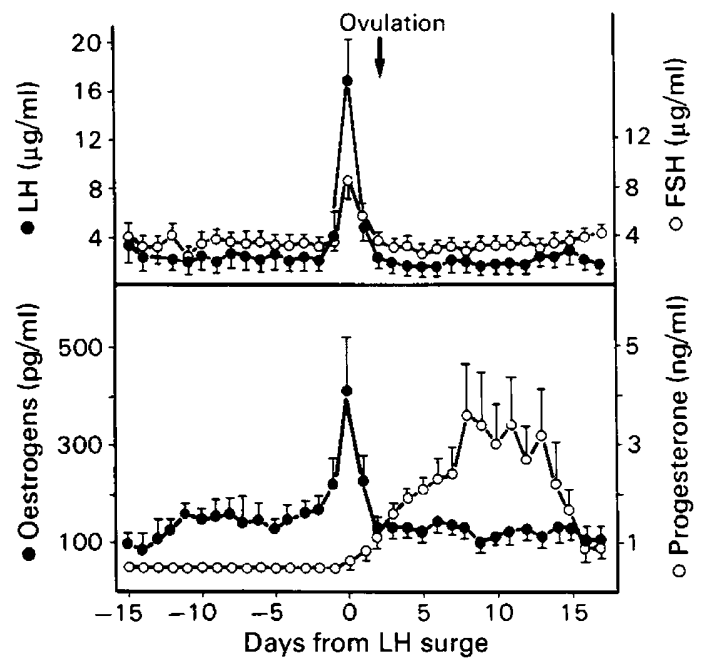

Text-fig. 1. Serum concentrations (mean \pm s.e.m.) of gonadotrophins and ovarian steroids throughout the menstrual cycle in monkeys. (From Wehrenberg et al., 1980.) 
the Graafian follicle into a corpus luteum, which secretes mainly progesterone. The life span of the corpus luteum is limited to 2 weeks unless fertilization and pregnancy occur. The decrease in progesterone concentrations resulting from luteal degeneration leads to menstruation and to a new follicular phase.

\section{Gonadotrophin release is pulsatile}

At first sight (Text-fig. 1), the daily blood hormone concentrations suggest uneventful secretory patterns for gonadotrophins, except at the time of the mid-cycle surge. However, frequent blood sampling clearly reveals that $\mathrm{LH}$ and FSH release from the pituitary does not occur at a continuous and steady rate but is the result of intermittent discharges of the hormones (Yamaji, Dierschke, Bhattacharya \& Knobil, 1972). As was later shown for other anterior pituitary hormones, the secretion of gonadotrophins is pulsatile. Examples of characteristic pulsatile secretory patterns of LH are illustrated in Text-fig. 2, which depicts changes in LH concentrations at 15-min intervals over periods of 6-8 h, at 4 different stages of the human menstrual cycle (Yen, Tsai, Naftolin, Vandenberg \& Ajabor, 1972).

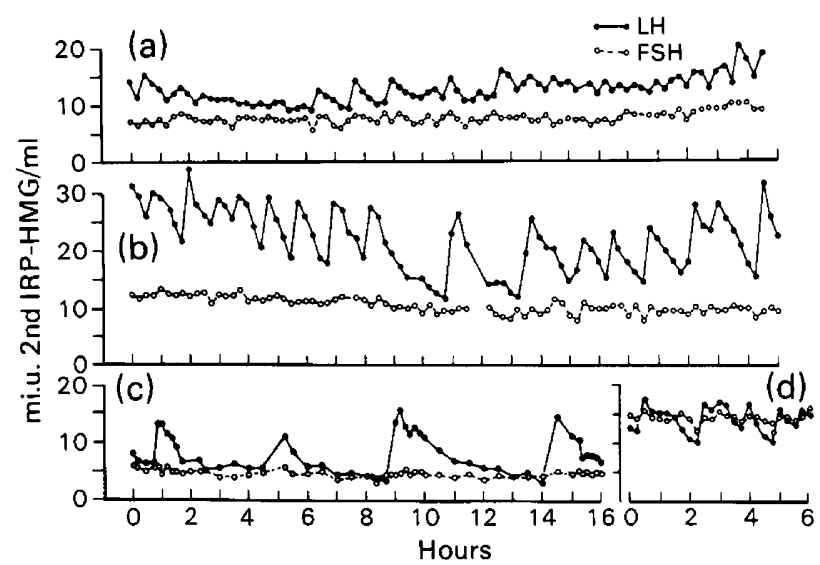

Text-fig. 2. Variations in the frequency and the magnitude of the pulsatile pattern of circulating gonadotrophins during different phases of the menstrual cycle: (a) preovulatory, Day 12; (b) post-ovulatory, Day 15; (c) late luteal phase, Day 26; (d) early follicular phase, Day 2. (From Yen et al., 1974.)

\section{Neurohormonal control of gonadotrophin secretion}

As in most other species, the activity of the gonadotroph in the primate is critically dependent upon hypothalamic gonadotrophin-releasing hormone $(\mathrm{Gn}-\mathrm{RH})$. Isolation of the anterior pituitary from the hypothalamus, as after pituitary stalk section (Vaughan et al., 1980), or neutralization of endogenous Gn-RH by administration of antiserum to this decapeptide (McCormack, Plant, Hess \& Knobil, 1977), results in an abrupt decrease in plasma gonadotrophin concentrations.

As $\mathrm{Gn}-\mathrm{RH}$ is the neuroendocrine signal responsible for gonadotrophin secretion, it is worthwhile at this point to review Gn-RH pathways in the central nervous system (Textfig. 3). In contrast to the rodent, Gn-RH cell bodies in the monkey can clearly be seen in the arcuate nucleus situated within the medial basal hypothalamus (Silverman, Antunes, Ferin \& Zimmerman, 1977). Their axons are directed towards the median eminence and terminate in the vicinity of the long portal vessels, which descend along the pituitary stalk to irrigate the anterior pituitary gland. This Gn-RH pathway appears to be a major one in the monkey, in so far as the control of gonadotrophin secretion is concerned; lesion of the arcuate nucleus results in a rapid decrease in the circulating concentrations of both LH and FSH (Plant et al., 1978a). As in the rodent, another Gn- 
RH pathway originates from the anterior hypothalamic-preoptic area, its fibres terminating in the organum vasculosum laminae terminalis (OVLT) or extending along the surface of the optic nerve to the median eminence. A third pathway can be traced from the hypothalamus into the pituitary stalk, its fibres descending along the stalk to reach the neurohypophysis. The significance of this pathway, apparently unique to the primate, and the location of its cell bodies remain unknown. This observation, however, confirms the finding of large concentrations of the neurohormone in the posterior pituitary by radioimmunoassay (Neill, Patton, Dailey, Tsou \& Tindall, 1976) and leads to the possibility that Gn-RH could reach the anterior pituitary from the neurohypophysis via the short portal vessels.

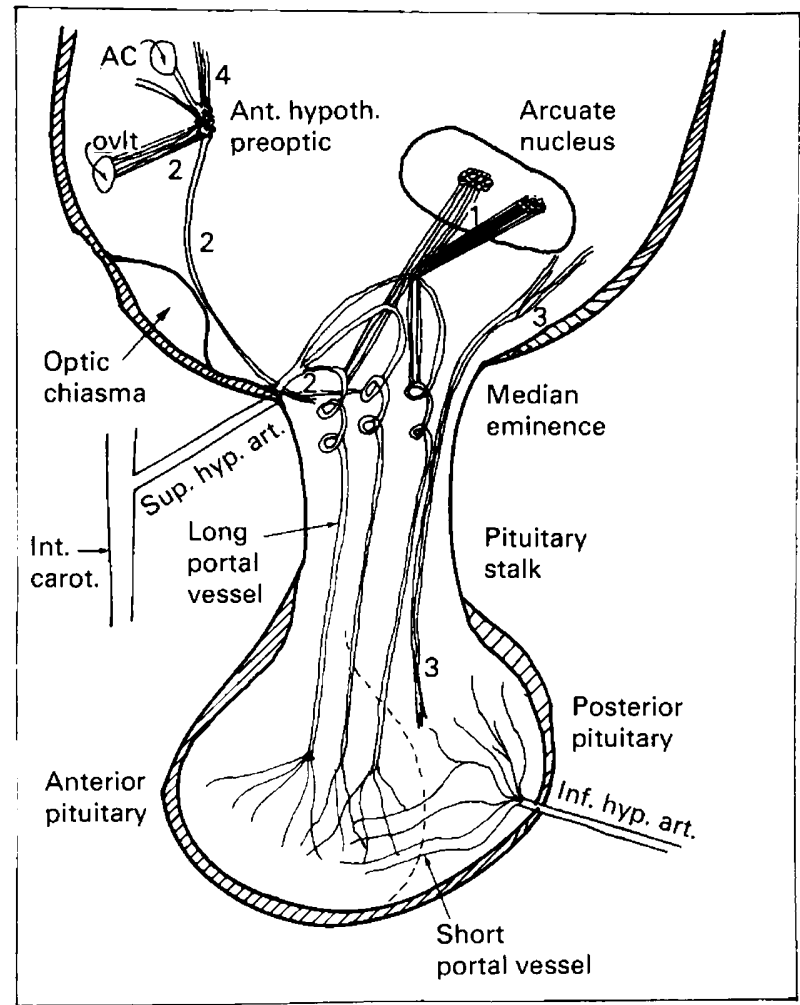

Text-fig. 3. Schematic representation of the Gn-RH network in the monkey. (1) The main GnRH pathway originates in the arcuate nucleus and terminates in the median eminence at the site of origin of the long portal vessels. (2) Tracts from the anterior hypothalamic-preoptic area to the organum vasculosum laminae terminalis (ovlt) and to the median eminence. (3) Tracts from the hypothalamus to the posterior pituitary. (4) Tracts from the anterior commissure (AC) into the limbic system. (From Ferin, 1982.)

It is now known that the signal for pulsatile gonadotrophin release originates within the brain and is the result of pulsatile activity of the hypothalamus and not of an inherently pulsatile property of the anterior pituitary gonadotroph. Indeed, we have clearly shown that the release of Gn-RH into the hypothalamo-hypophysial portal circulation of ovariectomized monkeys fluctuates with a pulse frequency similar to that of $\mathrm{LH}$ in the peripheral blood, i.e. at intervals of $60-180 \mathrm{~min}$ (Carmel, Araki \& Ferin, 1976) (Text-fig. 4). The neural oscillator responsible for pulsatile Gn-RH discharges is now thought to be located within the medial basal hypothalamic area, and is presumably contained within the principal Gn-RH pathway (arcuate $\rightarrow$ median eminence) described above. Indeed, isolation of the arcuate nucleus from the remainder of the central nervous 
system by medial basal hypothalamic deafferentation does not prevent pulsatile gonadotrophin discharges (Krey, Butler \& Knobil, 1975). Most recently, monitoring of multiunit activity in the vicinity of the main Gn-RH pathway in the monkey indicated increases in electrical activity coincident with the initiation of each LH pulse (Knobil, 1981). Similar parallel changes in multiunit activity of the median eminence have been observed in the ewe (Thiery \& Pelletier, 1981).

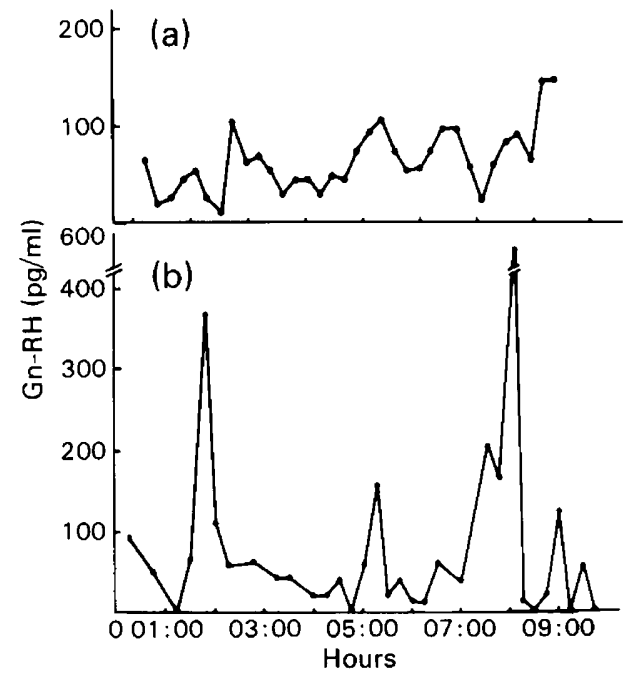

Text-fig. 4. Pulsatile Gn-RH release into the hypothalamo-hypophysial portal circulation of (a) a monkey during the follicular phase and (b) an ovariectomized monkey. Stalk portal blood was collected continuously for about $10 \mathrm{~h}$. Each point represents Gn-RH concentration (as measured by radioimmunoassay) for a 15-20-min period. (Adapted from Carmel et al., 1976.)

\section{Significance of pulsatile $\mathrm{G} n-\mathrm{RH}$ secretion}

The physiological significance of the Gn-RH oscillatory patterns of secretion remained unknown, until several investigators reported their futile attempts to restore or induce gonadotrophin secretion in hormone-deficient animals, using either continuous $\mathrm{Gn}-\mathrm{RH}$ infusions or long-acting $\mathrm{Gn}-\mathrm{RH}$ analogues. In our laboratory, for example, we had been quite unsuccessful in restoring LH or FSH secretion in pituitary stalk-sectioned monkeys, even after prolonged continuous Gn-RH therapy; although increases in gonadotrophin secretion were observed during the initial hours of the treatment, these were short-lived and hormone concentrations quickly returned to post-surgical undetectable levels. The failure to restore normal secretion in these animals was not related to necrosis of the pituitary gland and a consequent inability of the gland to respond to the Gn-RH stimulus; rather, we now know that it was the consequence of an unphysiological mode of administration of the decapeptide. Indeed, when later $\mathrm{Gn}-\mathrm{RH}$ infusions to stalk-sectioned monkeys (Text-fig. 5) or to animals bearing arcuate lesions (Nakai, Plant, Hess, Keogh \& Knobil, 1978) mimicked the physiological pulsatile mode of Gn-RH release, normal gonadotrophin secretion could be restored. These results clearly underline the crucial significance of hypothalamic pulsatile release patterns. Similarly, in the human, increased gonadotrophin secretion could be induced in patients with Kallman's syndrome, presumably lacking Gn-RH, by hourly pulsatile infusions of $\mathrm{Gn}-\mathrm{RH}$, using battery driven portable infusion pumps (Crowley \& McArthur, 1980).

The underlying mechanisms by which desensitization of the pituitary gland occurs following continuous, but not intermittent, infusions of Gn-RH remain to be determined. The same phenomenon has been shown in vitro; superfused pituitaries subjected to continuous stimulation by 


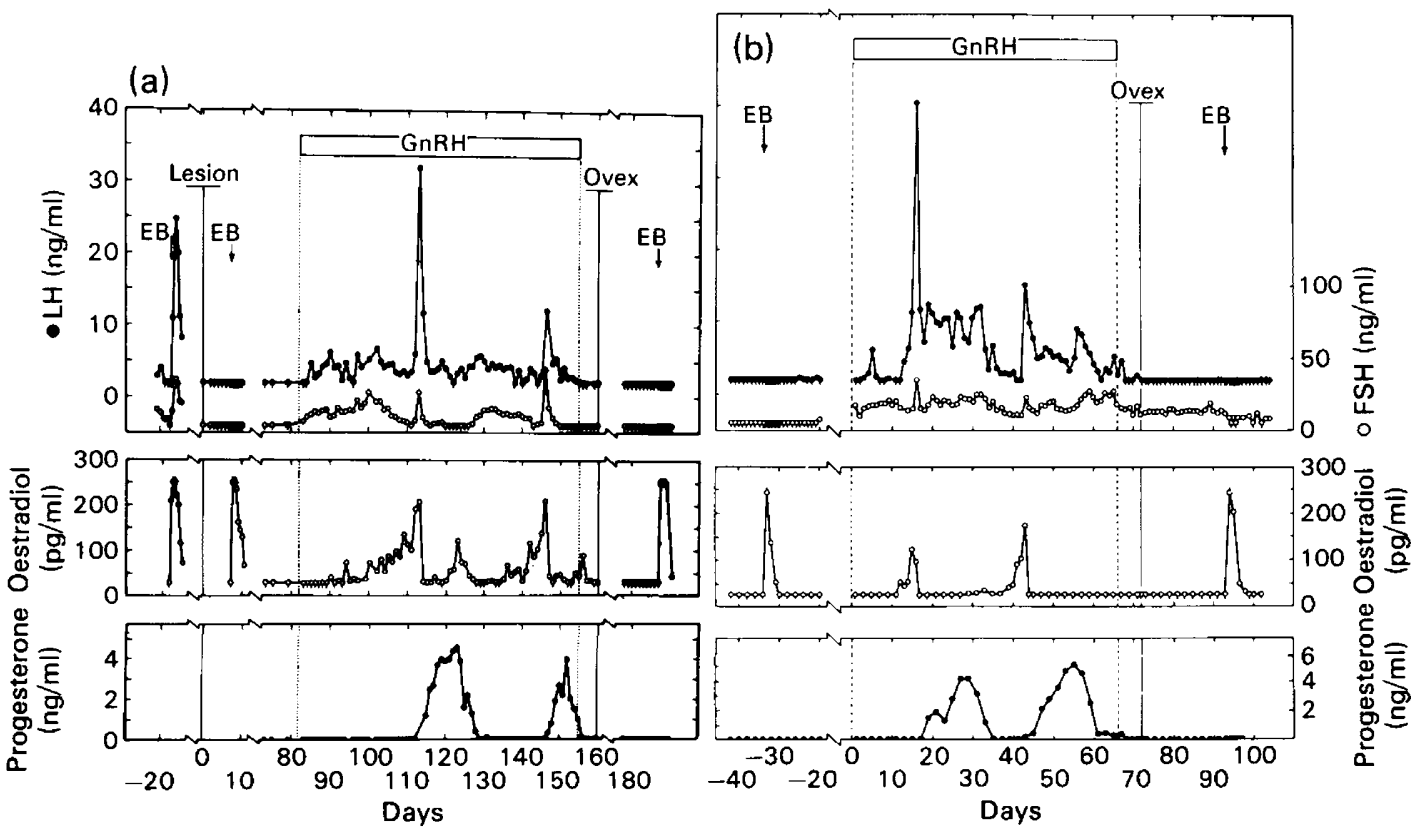

Text-fig. 5. Induction of menstrual cycles by the administration of unvarying (hourly) Gn-RH pulses in (a) a monkey in which the arcuate nucleus has been lesioned and (b) a pituitary stalksectioned monkey, several months after the operation. The lesion in both animals had abolished gonadotrophin secretion. An oestrogen challenge (EB) given after the lesion was unable to induce the LH and FSH surge seen in control animals. Gn-RH infusion elicited 2 menstrual cycles, with an interval between the 2 gonadotrophic surges of 33 and 28 days in each animal respectively. After discontinuation of the infusion, neither the oestrogen challenge nor ovariectomy (ovex) stimulated gonadotrophin secretion. (Adapted from Knobil 1980.)

Gn-RH or by potent $\mathrm{Gn}-\mathrm{RH}$ analogues also decrease their output of LH rapidly (Smith \& Vale, 1981 ; Yeo, Grossman, Belchetz \& Besser, 1981). It has been suggested that this phenomenon might involve a 'down-regulation' of the Gn-RH receptor (Nett, Crowder, Moss \& Duello, 1981). However, while changes in the number of pituitary membrane Gn-RH receptors have been shown following Gn-RH stimulation, these do not necessarily explain insensitivity, as in some cases increases rather than decreases in receptor numbers occurred during the prolonged stimulation period. The Gn-RH-desensitized cells are not refractory to all secretagogues, because agents mobilizing $\mathrm{Ca}^{2+}$ remain effective in releasing gonadotrophins from a 'down-regulated' gland. Whatever future research may yield, it is clear that continuous turnover of $\mathrm{Gn}-\mathrm{RH}$ at its receptor is necessary for continued stimulation of LH secretion.

\section{Modulation of the Gn-RH arcuate neural oscillator}

As suggested by Knobil (1980) the Gn-RH arcuate neural oscillator described above could be viewed as a transducer of neural signals into endocrine signals, translating frequency, the language of the nervous system, into changing circulating hormone levels, the language of the endocrine system. There is accumulating evidence that the activity of the neural oscillator can be modified by experimental manipulation. For instance, the frequency characteristic of the LH pulse in ovariectomized monkeys can be significantly decreased by deep pentobarbitone anaesthesia. However, this effect is accompanied by a lengthening in the duration of the pulse, leaving the total amount of LH that is released unchanged (Wehrenberg \& Ferin, 1981). Studies of the properties of the Gn-RH neural oscillator and of the factors which may modulate its activity are hampered by 
difficulties in assessing Gn-RH changes directly and must therefore rely upon an indirect approach, such as the measurement of LH output. This is particularly unfortunate: results obtained under these conditions are difficult to interpret because changes in LH secretion may not only be the consequence of changes in Gn-RH secretion but also of a direct modulation at the level of the anterior pituitary gland. It is thought, however, that at least some of the changes in LH secretion observed in the circumstances described below are related to a direct modulation of the Gn-RH neural oscillator.

The role of ovarian steroids. The characteristics of pulsatile LH secretion in the human vary with the endocrine milieu. As illustrated in Text-fig. 2, amplitude and frequency of the LH pulse differ at various stages of the menstrual cycle (Yen et al., 1972). These changes in LH pulsatile characteristics are attributed to effects exerted by oestradiol and progesterone on the arcuate nucleus-pituitary axis. In ovariectomized animals, the administration of oestradiol produces a rapid decrease in LH levels, a result of the 'classical' oestradiol negative feedback loop. In the ovariectomized sheep, there is clear evidence to indicate that the negative feedback effect of oestradiol on gonadotrophins is related to a decrease in the LH pulse amplitude but not in its frequency (Goodman \& Karsch, 1980). To these authors, this would appear consistent with a direct effect of oestradiol on the pituitary, as they also cite data to support the fact that oestradiol can decrease the LH response to Gn-RH (Terasawa, Bridson, Weishaar \& Rubens, 1980) and that an effect of oestradiol at the hypophysial level may account for the negative feedback action of oestradiol (Plant, Nakai, Belchetz, Keogh \& Knobil, 1978b). That this conclusion may not be entirely justified is indicated by preliminary results obtained in our laboratory on Gn-RH concentrations in hypothalamo-hypophysial portal blood in 2 monkeys during the early midfollicular phase (Text-fig. 4). These show that, in comparison to the ovariectomized monkey, the amplitude of the Gn-RH pulse is decreased (while its frequency appears unchanged), suggesting a direct effect of oestradiol on the neural oscillator. Other experimental results in the monkey (Ferin, Carmel, Zimmerman, Warren \& Vande Wiele, 1974a; Chappel, Resko, Norman \& Spies, 1981) also indicate possible hypothalamic sites of action for the negative feedback of oestradiol. Until further experimentation, we must then conclude that oestradiol may act at both an hypothalamic and hypophysial site to decrease the amplitude of the LH pulse. Changes in frequency which are observed late in the follicular phase would be expected to result from a central action of oestradiol. One cannot, however, completely discount the possibility that changes in frequency occur as a result of a direct hypophysial effect of oestradiol, as this steroid may in fact sensitize or desensitize the gonadotroph in such a way that would allow or prevent the expression of a $\mathrm{LH}$ pulse in response to the GnRH pulse. Abundant uptake of oestradiol in hypophysial and hypothalamic sites in the monkey (Pfaff et al., 1976) indicates that this steroid could act at either site.

The decrease in the frequency of the LH pulse as the luteal phase progresses (Text-fig. 2) may be related to an effect of progesterone. Administration of progesterone to ovariectomized sheep results in a decrease in the frequency of LH pulses, without reduction in the amplitude or in the LH response to exogenous Gn-RH (Goodman, Bittman, Foster \& Karsch, 1981). Addition of low amounts of oestradiol to progesterone results in a further reduction in the LH pulse frequency, which indicates that there is a synergism between the 2 steroids, which may reflect an oestradiolinduced increase in the sensitivity of the brain to the negative feedback action of progesterone.

The role of endogenous opiates. Indirect evidence suggests that the effect of progesterone on pulsatile LH release patterns may in turn be mediated by endogenous opioid peptides. We have performed several studies on monkeys. The hypothalamic pathways of endogenous opioid peptides were studied by immunocytochemistry: cell bodies were found to be located within the arcuate nucleus and some of their axons to terminate at the site of origin of the long portal vessels. Subsequently, measurements of $\beta$-endorphins (by radioimmunoassay) in hypothalamohypophysial portal blood revealed that, under certain conditions, this opioid peptide is released in high concentrations (Wardlaw, Wehrenberg, Ferin, Carmel \& Frantz, 1980). A hypothalamic rather than hypophysial origin for pituitary portal $\beta$-endorphin is suggested by the fact that portal $\beta$ - 
endorphin concentrations remain unchanged after hypophysectomy and that the elution profile of portal $\beta$-endorphin immunoactivity on Sephadex G-50 is similar to that of hypothalamic but not hypophysial extracts (Wardlaw, Wehrenberg, Ferin, Antunes \& Frantz, 1982). We have therefore used $\beta$-endorphin immunoreactivity in pituitary-stalk portal blood as an index of hypothalamic opiate activity and monitored it under various hormonal conditions. The results indicate that hypothalamic $\beta$-endorphin activity is clearly modulated by ovarian steroids. In the absence of significant oestradiol and progesterone concentrations, such as after ovariectomy or at menstruation, $\beta$-endorphin immunoreactivity in portal blood is undetectable (Text-fig. 6) (Wehrenberg, Wardlaw, Frantz \& Ferin, 1982). Hypothalamic $\beta$-endorphin activity increases in the presence of oestradiol and to a greater degree in the presence of both oestradiol and progesterone, as seen during the luteal phase or after replacement of both steroids in ovariectomized monkeys (Text-fig. 6). It is tempting to speculate that these large fluctuations in hypothalamic $\beta$-endorphin activity have some modifying effect on gonadotrophin secretory patterns. Indeed, in the monkey as in other species, opiates have been shown to decrease LH secretion (Ferin, Wehrenberg, Lam, Alston \& Vande Wiele, 1982). This effect is apparently related to a decrease in the frequency of the LH pulse. Increased hypothalamic $\beta$-endorphin activity in the presence of progesterone may therefore be responsible for the decrease in LH pulse frequency observed during the luteal phase or after progesterone administration. In support of this hypothesis is the fact that infusion of naloxone (an opiate antagonist) into women during the luteal phase appears to increase the frequency of the LH pulse (Ropert, Quigley \& Yen, 1981). This effect of $\beta$ endorphin on gonadotrophin release may result from an action at a hypothalamic site; indeed, opiate injection to pituitary stalk-sectioned monkeys (in which the pituitary gland is isolated from the brain) does not prevent the LH response to Gn-RH pulses (Ferin et al., 1982). Therefore, $\beta$ endorphin may interact with opiate receptors in the medial basal hypothalamus to decrease the release of Gn-RH, as is suggested from experiments with superfused hypothalami (Wilkes \& Yen, 1981).

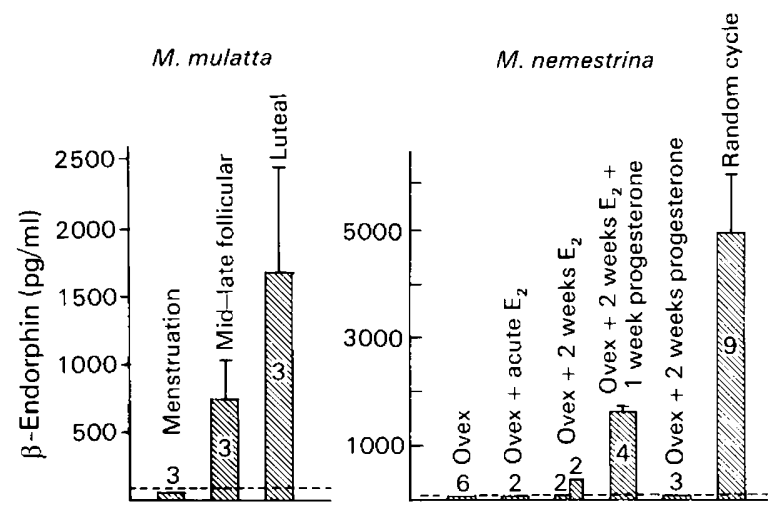

Text-fig. 6. Hypothalamic $\beta$-endorphin activity (as monitored by radio-immunoassay in pituitary stalk portal blood) of rhesus ( $M$. mulatta) and pigtailed ( $M$. nemestrina) monkeys at 3 stages of the menstrual cycle (left), randomly (but not at menstruation) during the menstrual cycle (right), or after ovariectomy and acute or chronic replacement with oestradiol, progesterone or both hormones. (Adapted from Wehrenberg et al., 1982, and Wardlaw et al., 1982.)

The role of biogenic amines. Dopamine, administered peripherally, has been shown to inhibit LH secretion in agonadal women (Judd, Rigg \& Yen, 1979). Intraventricularly administered dopamine in the rat suppresses LH by a decrease in the frequency of the pulsatile LH discharge, pulse amplitude remaining unchanged (Gallo, 1981). The effects of other biogenic amines and neurotransmitters remain to be investigated in the primate. 


\section{The significance of changes in pulsatile $\mathrm{Gn}-\mathrm{RH}$ secretion}

The physiological significance of changes in the characteristics of pulsatile Gn-RH release on pituitary secretion and on the hypophysial-ovarian axis remains to be determined. In a fascinating study by Wildt $e t$ al. (1981), comparing the effects of various Gn-RH frequencies on gonadotrophin secretion in monkeys bearing arcuate nucleus lesions, it was found that reduction of the frequency of the Gn-RH pulse from 1 pulse/ $\mathrm{h}$ to 1 pulse $/ 3 \mathrm{~h}$ resulted in increased FSH levels and a change in the $\mathrm{LH} / \mathrm{FSH}$ ratio, favouring FSH at the lower frequency. Such a result would indicate that a decrease in the frequency of the Gn-RH pulse can profoundly alter not only the concentrations of FSH, but also the ratio of the 2 gonadotrophins. Experiments using a Gn-RH frequency greater than that physiologically observed caused a gradual reduction in circulatory gonadotrophins, which became undetectable with frequencies greater than 2 pulses $/ \mathrm{h}$. While further experimentation in this direction is needed, it is tempting to speculate that patients showing a high LH/FSH ratio, such as those suffering from the polycystic ovarian syndrome, may do so as a result of alterations in endogenous pulsatile $\mathrm{Gn}-\mathrm{RH}$ patterns.

\section{The mid-cycle gonadotrophin surge and its steroid feedback control}

In most species, the mid-cycle ovulatory gonadotrophin surge occurs following a large increase in circulating oestradiol concentrations, the secretory product of the large mature Graafian follicle (Text-fig. 1). There is considerable experimental evidence linking this oestradiol rise to the LH surge. In the monkey, an LH surge similar to that seen spontaneously at mid-cycle (positive feedback loop of oestradiol) can be induced during the early follicular phase (at a time of the cycle when spontaneous LH surges are not seen) by administering oestradiol in amounts simulating those seen at mid-cycle (Karsch et al., 1973). Inactivation of the oestradiol signal by immunization to oestrogen blocks the mid-cycle LH rise and ovulation; in these immunized monkeys, the LH surge and ovulation can be restored by diethylstilboestrol, a synthetic oestrogen not recognized by antioestradiol antibodies (Ferin, Dyrenfurth, Cowchock, Warren \& Vande Wiele, 1974b). Progesterone has been shown to influence the oestradiol-induced LH surge in a biphasic manner. During the follicular phase of the menstrual cycle, little or no progesterone is secreted. At mid-cycle however, as the LH surge occurs, small amounts of progesterone are released (preovulatory progesterone rise). At these concentrations, the steroid has been shown to advance the time of maximal gonadotrophin release (Helmond, Simons \& Hein, 1981). However, at higher concentrations, such as those seen during the luteal phase, progesterone inhibits the oestrogen-induced LH surge (Spies \& Niswender, 1972).

\section{The feedback sites controlling the gonadotrophin surge}

Several attempts have been made to delineate the site(s) at which ovarian steroids act to control the mid-cycle ovulatory LH surge. In the classical model, which derives from studies in rodents, the primary site of action of oestradiol was thought to reside within the preoptic-anterior hypothalamic area (Text-fig. 7). Local injections of oestradiol in this area initiate a signal which, when it reaches the median eminence, culminates in a surge of $\mathrm{Gn}-\mathrm{RH}$ and a subsequent release of LH (Fink \& Jamieson, 1976; Goodman, 1978). Interruption of this pathway by deafferentation prevented the oestradiol-positive feedback and resulted in a lack of LH surges and anovulation (Halasz \& Pupp, 1969). Initial experiments indicated that the model may be different in monkeys. Indeed, local injections of oestradiol into the preoptic-anterior hypothalamic area did not induce $\mathrm{LH}$ surges (M. Ferin \& W. P. Diefenbach, unpublished observations) and medial basal hypothalamic deafferentation, isolating the arcuate region from the remainder of the brain, did not interrupt normal menstrual cycles and ovulation (Krey et al., 1975; Ferin et al., 1977). In fact, LH and FSH surges, identical to those obtained in intact control animals, were induced in monkeys in which the 
(a) Rat

(b) Monkey

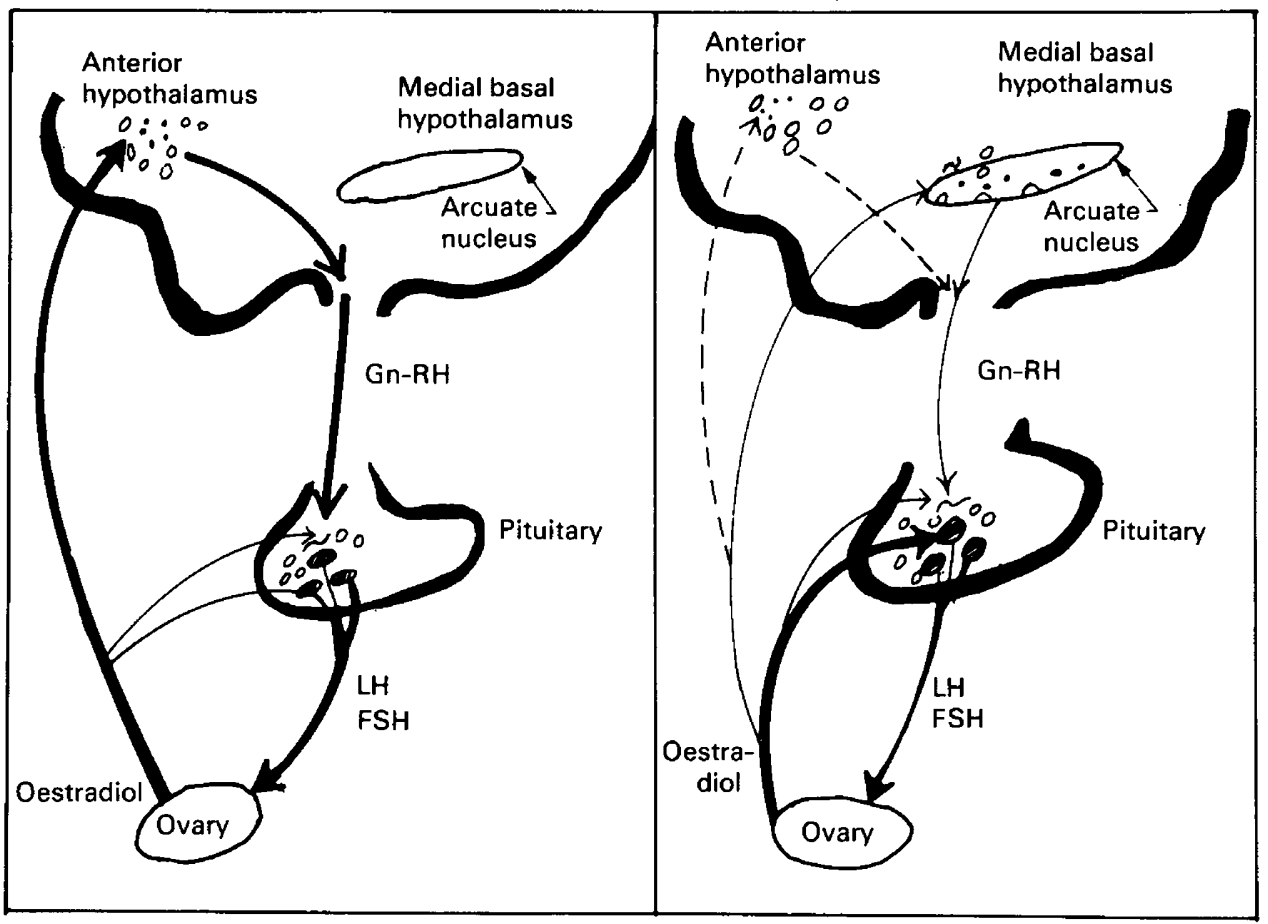

Text-fig. 7. Postulated differences in the site of the positive feedback action of oestradiol in the rat and the monkey (see text for details).

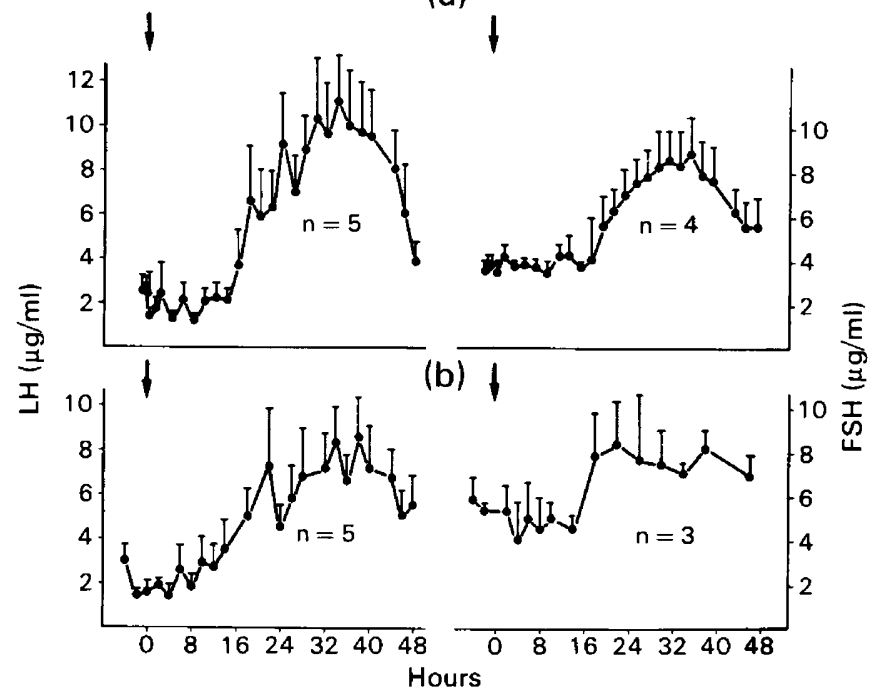

Text-fig. 8. LH and FSH responses to an oestradiol challenge (arrow) in monkeys (a) before and

(b) immediately after section of the pituitary stalk. (From Ferin et al., 1979.)

pituitary had been isolated from the hypothalamus by pituitary stalk section (Ferin, Rosenblatt, Carmel, Antunes \& Vande Wiele, 1979) (Text-fig. 8). (This experiment has to be performed within hours of surgery, because separation of the pituitary from the brain rapidly depletes the hypophysial LH stores.) 
These results in a primate species imply (1) that the positive oestradiol feedback may occur at an anterior pituitary site, and (2) that the LH surge can occur in the absence of a preceding surge of $\mathrm{Gn}-\mathrm{RH}$ (since the stalk portal vessels had been sectioned before the oestradiol challenge). These conclusions are supported by experiments in which apparently normal menstrual cycles were restored in pituitary stalk-sectioned monkeys or in animals bearing arcuate lesions following administration of unvarying (hourly) Gn-RH pulses (Text-fig. 5) (Knobil, 1980).

In the monkey, the site at which progesterone facilitates LH secretion is thought to be hypophysial. In contrast, the inhibitory effect of progesterone on the oestradiol-induced LH surge occurs at a hypothalamic site, because progesterone is ineffective in animals bearing lesions of the arcuate region (Pohl, Richardson, Marshall \& Knobil, 1982). These authors suggest that progesterone may cause the production of an inhibitory factor within the central nervous system, which acts on the pituitary to inhibit the positive feedback action of oestradiol.

\section{A model for the menstrual cycle}

Based upon the above experimental observations, menstrual cyclicity in the monkey can be described as the result of the activity of several components: (1) the arcuate nucleus (the neural oscillator) which, at regular intervals, signals the release of Gn-RH pulses into the hypothalamohypophysial portal circulation; (2) the anterior pituitary gland, which upon intermittent stimulation by Gn-RH releases $\mathrm{LH}$ and FSH, (3) the ovary, in which the follicles, when stimulated by FSH and $\mathrm{LH}$, undergo morphological and secretory changes, resulting in a rapid release of oestradiol, which acts directly at the pituitary level to induce the mid-cycle gonadotrophin surge and ovulation. Progesterone secreted by the ensuing corpus luteum prevents further LH surges. Such a model for the menstrual cycle would not require an increment in Gn-RH prior to the LH surge. (LH release at mid-cycle undoubtedly is greatly facilitated by the reported increase in responsiveness of the gonadotroph to Gn-RH in the presence of high oestrogen levels (Ferin, Warren, Dyrenfurth, Vande Wiele \& White, 1974c).) This primate model postulates a permissive role of the hypothalamus but a primary role of the ovary in the timing of the LH surge and contrasts with the rat model, in which timing of the LH surge is regulated by the hypothalamus (Text-fig. 7). The postulated differences in oestrogen feedback sites in the 2 species reflect equivalent variations in the Gn-RH anatomical pathways. While the main Gn-RH pathway in the monkey appears to originate from the arcuate nucleus (Text-fig. 3), in the rat it appears to bypass the arcuate nucleus and connect the preoptic-anterior hypothalamic area directly to the median eminence. The anatomical difference may promote independent activity of the Gn-RH-pituitary axis in the monkey and remove it further from environmental influences, which in the rat play a major role in the timing of the $\mathrm{LH}$ surge.

Although the proposed primate model adequately describes the experimental model from which it is derived (i.e. the stalk-sectioned or arcuate-lesioned monkey treated with hourly pulses of $\mathrm{Gn}-\mathrm{RH}$ ), it is in fact too simplistic and does not explain all of the complex physiological changes observed during the spontaneous menstrual cycle. For example, the model postulates unchanging activity of the arcuate neural oscillator, when, as reported above, this activity is known or presumed to change with varying hormonal conditions during the cycle. Studies of these changes in activity and of their importance in the normal function of the menstrual cycle need to be undertaken. The postulated model also removes the arcuate-pituitary axis entirely from other brain influences. This may not entirely reflect physiological situations, as other neural influences may impinge upon the activity of the arcuate oscillator, even during the normal menstrual cycle. Conditions under which this may occur are not entirely known. However, it has been shown that disconnection or lesion of the anterior hypothalamic-preoptic area in the monkey results in a temporary disruption of the menstrual cycle (Norman, Resko \& Spies, 1976; Cogen, Antunes, Louis, Dyrenfurth \& Ferin, 1980). This is in contrast to medial basal hypothalamic disconnection which does not affect menstrual cyclicity (see above). The contrasting results of these two experiments may indicate the 


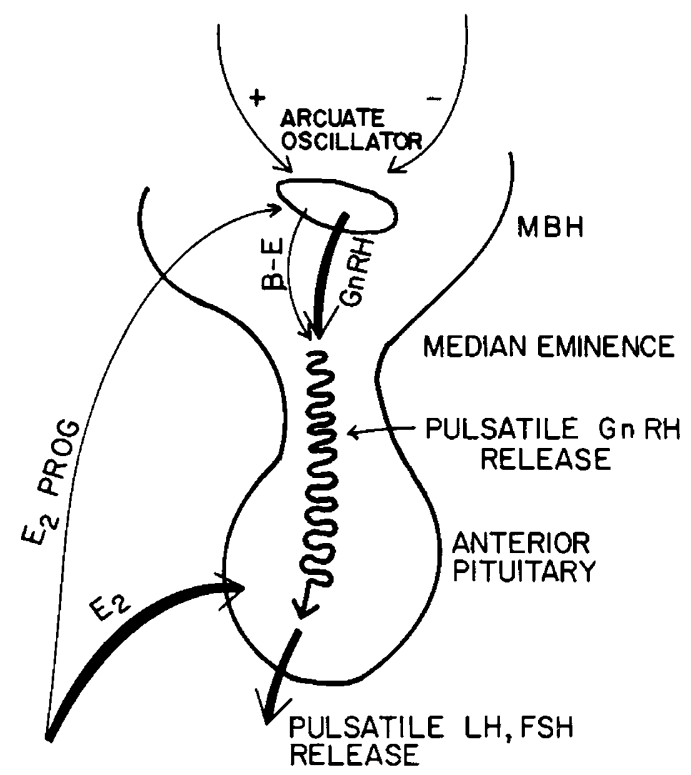

Text-fig. 9. Postulated control of gonadotrophin release in the primate. Pulsatile gonadotrophin release is the result of pulsatile Gn-RH release into the hypophysial portal circulation. The oscillator responsible for pulsatile Gn-RH release into hypophysial portal blood is located within the medial basal hypothalamus $(\mathrm{MBH})$. Higher neural influences (both stimulatory and inhibitory) impinge upon the activity of the oscillator, while $\beta$-endorphin $(\beta-E)$ may influence the characteristics of pulsatile Gn-RH release. Both oestradiol and progesterone modulate the activity of the arcuate oscillator, while oestradiol also acts on the pituitary gland to modulate the response of the gonadotroph to Gn-RH and to act as a gonadotrophin-releasing factor insofar as the gonadotrophin surge is concerned.

existence of higher centres influencing arcuate oscillator activity and impinging on the expression of frequency and amplitude of the $\mathrm{Gn}-\mathrm{RH}$ pulse. These influences may be stimulatory and inhibitory, the anterior lesion, for example, removing a positive stimulatory input, with a resulting temporary overriding inhibitory input on the arcuate oscillator. However, although the arcuatemedian eminence Gn-RH pathway appears to be the most important in the monkey, secondary pathways link the median eminence to the rostral and posterior regions of the hypothalamus, thereby bypassing the arcuate nucleus. The factors that influence the activity of the arcuate oscillator and of the anterior pituitary gland are depicted schematically in Text-fig. 9. The role for these neural influences remains to be fully characterized, not only during the normal spontaneous menstrual cycle but also in the genesis of, for example, 'hypothalamic' amenorrhoea. In this regard, it has been known that the suckling stimulus is a condition under which inhibition of the neural oscillator is known to occur (Schallenberger, Richardson \& Knobil, 1981).

\section{References}

Carmel, P.W., Araki, S. \& Ferin, M. (1976) Pituitary stalk portal blood collection in rhesus monkeys: evidence for pulsatile release of gonadotropin-releasing hormone. Endocrinology 99, 243-248.

Chappel, S.C., Resko, J.A., Norman, R.L. \& Spies, H.G. (1981) Studies in rhesus monkeys on the site where estrogen inhibits gonadotropins: delivery of $17 \beta$ estradiol to the hypothalamus and pituitary gland. $J$. clin. Endocr. Metab. 52, 1-8.
Cogen, P.H., Antunes, J.L., Louis, K.M., Dyrenfurth, I. \& Ferin, M. (1980) The effects of anterior hypothalamic disconnection on gonadotropin secretion in the female rhesus monkey. Endocrinology 107, 677683.

Crowley, W.F. \& McArthur, J.W. (1980) Simulation of the normal menstrual cycle in Kallman's syndrome by pulsatile administration of LHRH. J. clin. Endocr. Metab. 51, 173-175. 
Ferin, M. (1982) The neuroendocrinological control of the menstrual cycle. In Behavior and the Menstrual Cycle, pp. 23-42. Ed. R. Freeman. Marcel Dekker Inc., New York.

Ferin, M., Carmel, P.W., Zimmerman, E.A., Warren, M. \& Vande Wiele, R.L. (1974a) Location of intrahypothalamic estrogen responsive sites influencing $\mathbf{L H}$ secretion in the female rhesus monkey. Endocrinology 95, 1059-1068.

Ferin, M., Dyrenfurth, I., Cowchock, S., Warren, M. \& Vande Wiele, R.L. (1974b) Active immunization to $17 \beta$-estradiol and its effects upon the reproductive cycle of the rhesus monkey. Endocrinology 94, 765776.

Ferin, M., Warren, M., Dyrenfurth, I., Vande Wiele, R.L. \& White, W.F. (1974c) Response of rhesus monkeys to LHRH throughout the ovarian cycle. J. clin. Endocr. Metab. 38, 231-237.

Ferin, M., Antunes, J.L., Zimmerman, E.A., Dyrenfurth, I., Frantz, A.G., Robinson, A. \& Carmel, P.W. (1977) Endocrine function in female rhesus monkeys after hypothalamic disconnection. Endocrinology 101, $1611-1620$

Ferin, M., Rosenblatt, H., Carmel, P.W., Antunes, J.L. \& Vande Wiele, R.L. (1979) Estrogen-induced gonadotropin surges in female rhesus monkeys after pituitary stalk section. Endocrinology 104, 50-52.

Ferin, M., Wehrenberg, W.B., Lam, N.Y., Alston, E.F. \& Vande Wiele, R.L. (1982) Effects and site of action of morphine on gonadotropin secretion in the female rhesus monkey. Endocrinology 111, 1652-1656.

Fink, G. \& Jamieson, M.G. (1976) Immunoreactive LHRH in rat pituitary stalk blood: effects of electrical stimulation of the medial preoptic area. $J$. Endocr. 68, 71-87.

Gallo, R.V. (1981) Further studies on dopamine induced suppression of pulsatile LH release in ovariectomized rats. Neuroendocrinology 32, 187-192.

Goodman, R.L. (1978) The site of the positive feedback action of estradiol in the rat. Endocrinology 102, 151159.

Goodman, R.L. \& Karsch, F.J. (1980) Pulsatile secretion of LH: differential suppression by ovarian steroids. Endocrinology 107, 1286-1290.

Goodman, R.L., Bittman, E.L., Foster, D.L. \& Karsch, F.J. (1981) The endocrine basis of the synergistic suppression of $\mathbf{L H}$ by estradiol and progesterone. Endocrinology 109, 1414-1417.

Halasz, B. \& Pupp, L. (1969) The endocrine effects of isolation of the hypothalamus from the rest of the brain. In Frontiers in Neuroendocrinology, pp. 307351. Eds W. F. Ganong \& L. Martini. Oxford University Press.

Helmond, F.A., Simons, P.A. \& Hein, P.R. (1981) Strength and duration characteristics of the facilitory and inhibitory effects of progesterone on the estrogen-induced gonadotropin surge in the female rhesus monkey. Endocrinology 108, 1837-1842.

Judd, S.J., Rigg, L.A. \& Yen, S.S.C. (1979) The effects of ovariectomy and estrogen treatment on dopamine inhibition of gonadotropin and prolactin release. $J$. clin. Endocr. Metab. 49, 182-184.

Karsch, F.J., Weick, R.F., Butler, W.R., Dierschke, D.J., Krey, L.C., Weiss, G., Hotchkiss, J., Yamaji, T. \& Knobil, E. (1973) Induced LH surges in the rhesus monkey: strength-duration characteristics of the estrogen stimulus. Endocrinology 92, 1740-1747.

Knobil, E. (1980) The neuroendocrine control of the menstrual cycle. Recent Prog. Horm. Res. 36, 53-88.

Knobil, E. (1981) Patterns of hypophysiotropic signals and gonadotropin secretion in the rhesus monkey. Biol. Reprod. 24, 44-49.

Krey, L.C., Butler, W.R. \& Knobil, E. (1975) Surgical disconnection of the medial basal hypothalamus and pituitary function in the rhesus monkey. I. Gonadotropin secretion. Endocrinology 96, 1073-1087.

McCormack, J.T., Plant, T.M., Hess, D.L. \& Knobil, E. (1977) The effect of LHRH antiserum administration on gonadotropin secretion in the rhesus monkey. Endocrinology 100, 663-667.

Nakai, Y., Plant, T.M., Hess, D.L., Keogh, E.J. \& Knobil, E. (1978) On the sites of the negative and positive feedback action of estradiol in the control of gonadotropin secretion in the rhesus monkey. Endocrinology 102, 1008-1014.

Neill, J.D., Patton, J.M., Dailey, R.A., Tsou, R.C. \& Tindall, G.T. (1976) On the regions of the brain regulating $\mathrm{LH}$ secretion in the rhesus monkey. Endocrinology 98, A59.

Nett, T.M., Crowder, M.E., Moss, G.E. \& Duello, T.M. (1981) GnRH-receptor interaction. V. Down regulation of pituitary receptors for GnRH in ovariectomized ewes by infusion of homologous hormone. Biol. Reprod. 24, 1145-1155.

Norman, R.L., Resko, J.A. \& Spies, H.G. (1976) The anterior hypothalamus: how it affects gonadotropin secretion in the rhesus monkey. Endocrinology 99, 5971.

Pfaff, D.W., Gerlach, J.L., McEwen, B.S., Ferin, M., Carmel, P.W. \& Zimmerman, E.A. (1976) Autoradiographic localization of hormone-concentrating cells in the brain of the female rhesus monkey. J. comp. Neurol. 170, 279-294.

Plant, T.M., Krey, L.C., Moossy, J., McCormack, J.T., Hess, D.L. \& Knobil, E. (1978a) The arcuate nucleus and the control of gonadotropin and prolactin secretion in the female rhesus monkey (Macaca mulatta). Endocrinology 102, 52-62.

Plant, T.M., Nakai, Y., Belchetz, P., Keogh, E.J. \& Knobil, E. (1978b) The sites of action of estradiol and phentolamine in the inhibition of the pulsatile, circhoral discharges of LH in the rhesus monkey. Endocrinology 102, 1015-1018.

Pohl, C.R., Richardson, D.W., Marshall, G. \& Knobil, E. (1982) Mode of action of progesterone in the blockade of gonadotropin surges in the rhesus monkey. Endocrinology 110, 1454-1455.

Ropert, J.F., Quigley, M.E. \& Yen, S.S.C. (1981) Endogenous opiates modulate pulsatile $\mathrm{LH}$ release in humans. J. clin. Endocr. Metab. 52, 583-585.

Schallenberger, E., Richards, ,n, D.W. \& Knobil, E. (1981) Role of prolactin in the lactational amenorrhea of the rhesus monkey. Biol. Reprod. 25, 370-374.

Silverman, A.J., Antunes, J.L., Ferin, M. \& Zimmerman, E.A. (1977) The distribution of luteinizing hormonereleasing hormone in the hypothalamus of the rhesus monkey. Light microscopic studies using immuno peroxidase technique. Endocrinology 101, 134-142.

Smith, M.A. \& Vale, W.W. (1981) Desensitization to gonadotropin-releasing hormone observed in super- 
fused pituitary cells on cytodex beads. Endocrinology 108, 752-759.

Spies, H.G. \& Niswender, G.D. (1972) Effect of progesterone and estradiol on $\mathrm{LH}$ release in rhesus monkeys. Endocrinology 90, 257-262.

Terasawa, E., Bridson, W.E., Weishaar, D.J. \& Rubens, L.V. (1980) Influence of ovarian steroids on pituitary sensitivity to LHRH in the ovariectomized guinea pig. Endocrinology 106, 425-429.

Thiery, J.C. \& Pelletier, J. (1981) Multiunit activity in the anterior median eminence and adjacent areas of the hypothalamus of the ewe in relation to $\mathrm{LH}$ secretion. Neuroendocrinology 32, 217-224.

Vaughan, L., Carmel, P.W., Dyrenfurth, I., Frantz, A.G., Antunes, J.L. \& Ferin, M. (1980) Section of the pituitary stalk in the rhesus monkey. I. Endocrine studies. Neuroendocrinology 30, 70-75.

Wardlaw, S.L., Wehrenberg, W.B., Ferin, M., Carmel, P.W. \& Frantz, A.G. (1980) High levels of $\beta$ endorphin in hypophyseal portal blood. Endocrinology 106, 1323-1326.

Wardlaw, S.L., Wehrenberg, W.B., Ferin, M., Antunes, J.L. \& Frantz, A.G. (1982) Effect of sex steroids on $\beta$ endorphin in hypophyseal portal blood. J. clin. Endocr. Metab. 55, 877-881.

Wehrenberg, W.B. \& Ferin, M. (1981) Modulation of pulsatile LH secretion in monkeys by pentobarbital anesthesia. Proc. Soc. exp. Biol. Med. 168, 286-289.

Wehrenberg, W.B., Dyrenfurth, I. \& Ferin, M. (1980) Endocrine characteristics of the menstrual cycle in the assamese monkey (Macaca assamensis). Biol. Reprod. 23, 522-525.
Wehrenberg, W.B., Wardlaw, S.L., Frantz, A.G. \& Ferin, M. (1982) $\beta$-endorphin in hypophyseal portal blood: variations throughout the menstrual cycle. Endocrinology 111, 879-881.

Wildt, L., Hausler, A., Marshall, G., Hutchinson, J.S., Plant, T.M., Belchetz, P.E. \& Knobil, E. (1981) Frequency and amplitude of GnRH stimulation and gonadotropin secretion in the rhesus monkey. Endocrinology 109, 376-385.

Wilkes, M.M. \& Yen, S.S.C. (1981) Augmentation by naloxone of efflux of LRF from superfused medial basal hypothalamus. Life Sci. 28, 2355-2359.

Yamaji, D.J., Dierschke, D.J., Bhattacharya, A.N. \& Knobil, E. (1972) The negative feedback control by estradiol and progesterone of $\mathrm{LH}$ secretion in the ovariectomized rhesus monkey. Endocrinology 90, 771-777.

Yen, S.S.C., Tsai, C.C., Naftolin, E., Vandenberg, C. \& Ajabor, L. (1972) Pulsatile patterns of gonadotropin release in subjects with and without ovarian function. J. clin. Endocr. Metab. 34, 671-675.

Yen, S.S.C., Vandenberg, G., Tsai, C.C. \& Parker, D.C. (1974) Ultradian fluctuations of gonadotropins. In Biorhythms and Human Reproduction, pp. 203-218. Eds M. Ferin, F. Halberg, R. M. Richart \& R. L. Vande Wiele. John Wiley, New York.

Yeo, T., Grossman, A., Belchetz, P. \& Besser, G.M. (1981) Response of luteinizing hormone from columns of dispersed rat pituitary cells to a highly potent analogue of luteinizing hormone releasing hormone. J. Endocr. 91, 33-41. 